OPEN ACCESS

Edited by:

Raul Zamora-Ros,

Institut d'Investigacio Biomedica de Bellvitge (IDIBELL), Spain

Reviewed by:

Justyna Godos,

University of Catania, Italy Luigi Santacroce,

University of Bari Aldo Moro, Italy

*Correspondence:

Rafael Perez-Araluce rperezar@unav.es

Specialty section: This article was submitted to

Nutritional Epidemiology,

a section of the journal

Frontiers in Nutrition

Received: 30 October 2021 Accepted: 13 December 2021

Published: 24 January 2022

Citation:

Perez-Araluce R, Martínez-González MÁ, Gea A and Carlos S (2022)

Components of the Mediterranean Diet and Risk of COVID-19.

Front. Nutr. 8:805533.

doi: 10.3389/fnut.2021.805533

\section{Components of the Mediterranean Diet and Risk of COVID-19}

\author{
Rafael Perez-Araluce ${ }^{1 *}$, Miguel Ángel Martínez-González ${ }^{1,2,3,4}$, Alfredo Gea $^{1,2,3}$ and \\ Silvia Carlos ${ }^{1,3}$
}

${ }^{1}$ Department of Preventive Medicine and Public Health, University of Navarra, Pamplona, Spain, ${ }^{2}$ Centro de Investigación Biomédica en Red de Fisiopatología de la Obesidad y la Nutrición, Instituto de Salud Carlos III, Madrid, Spain, ${ }^{3}$ Navarra Institute for Health Research, Pamplona, Spain, ${ }^{4}$ Department of Nutrition, Harvard T.H. Chan School of Public Health, Harvard University, Boston, MA, United States

Adherence to the traditional Mediterranean diet has been customarily assessed with the Mediterranean diet score (MDS or Trichopolou Index), with values of 0 or 1 assigned to each of the nine elements, and with the use of the sex-specific median as the cutoff. The value of persons whose consumption of the six beneficial items (ratio of monounsaturated to saturated fatty acids, vegetables, legumes, fruits and nuts, cereal, and fish) is at or above the median and is assigned a value of 1 . Otherwise they receive 0 points. For detrimental elements (meats and dairy products) persons whose consumption is below the median are assigned a value of 1 . An additional ninth point is assigned to moderate ethanol intake. We assessed the effect of each of the nine components of the MDS (replacing the fats ratio with olive oil, the main source of monounsaturated fats in the Mediterranean diet) on the risk of COVID-19 infection, symptomatic and severe COVID19. From March to December 2020, 9,699 participants of the "Seguimiento Universidad de Navarra" (SUN) cohort answered a COVID-19 questionnaire. After excluding doctors and nurses, 5,194 participants were included in the main statistical analyses. Among them, we observed 382 cases of COVID-19 based on symptoms and clinical diagnosis; 167 of them with test confirmation. For the two COVID-19 definitions used, we found a significant decrease in risk for a higher adherence to the Mediterranean diet $(\mathrm{OR}=0.64$, 95\% Cl: 0.42-0.98, $p$ for trend $=0.040$; and $\mathrm{OR}=0.44,95 \% \mathrm{Cl}: 0.22-0.88, p$ for trend $=0.020$, for test-diagnosed cases). A protective effect was also found for symptomatic COVID-19 (OR = 0.64, 95\% Cl: 0.41-1.00, $p$ for trend =0.050). Among the different individual food groups, only the consumption of whole dairy products showed a harmful direct association. The Mediterranean diet as a whole seems more important than each of its components in preventing the infection and symptoms of COVID-19.

Keywords: Mediterranean diet, SARS-CoV-2, COVID-19, dairy products, SUN project

\section{INTRODUCTION}

Since the beginning of the coronavirus disease-2019 (COVID-19) pandemic in December 2019 and by the end of October 2021 more than 245 million SARS-CoV-2 virus infections and near 5 million deaths had been notified (1).

It is now well-known that SARS-CoV-2 virus is mainly airborne-transmitted and thus, the most important preventive measures to avoid the inhalation of the virus are physical distancing, use of 
masks, and adequate ventilation (2). However, there are other non-hygiene related factors which can help reducing the risk of infection or its related clinical complications. As there are some comorbidities clearly associated with COVID-19, such as cardiovascular disease (CVD), type 2 diabetes, hypertension or obesity (3-7), in the long-term, previous adherence to a healthy lifestyle and diet could reduce the vulnerability of subjects to acquire the infection by reducing the burden of these chronic conditions. A key component of a healthy lifestyle is a balanced and healthy diet, which is in turn associated with an adequate immune response, as well as with antiinflammatory properties to reduce the risk of infections (8-13). Therefore, both the innate and adaptive immune cell functions against the entrance and replication of SARS-CoV-2 and the cytokine storm produced by this infection can be improved and modulated by the effect of an adequate nutritional status, in not-at-risk individuals as well as those with comorbidities (14). Additionally, diet is known to exert an impact on the human microbiota, which in turn can be associated with the risk of acquiring the virus or the development of symptoms after infection $(15,16)$.

The effect of nutrition on respiratory infections has been previously described $(17,18)$. Thus, early in June 2020 the World Health Organization Eastern Mediterranean Region Office published the "Nutrition advice for adults during the COVID-19 outbreak" supporting the relevance of nutrition on the pandemic (19). Additionally, since the very beginning of the pandemic, observational research and interventional studies focusing on nutritional aspects were carried out to find further non-pharmacological options and to prevent or reduce the health impacts of SARS-CoV-2 infection. Initially micronutrients were mainly analyzed, particularly vitamins $(20,21)$. Afterwards, the antioxidant, antiinflammatory, and antiviral activities of some nutrients and foods have been evaluated (6, 21-33). Less evidence is available for the effect of complete dietary patterns on COVID19 (4, 32, 34-38), and most published reports on dietary patterns are related to the changes in diet caused by the pandemic or the lockdown.

In a previous assessment of the SUN ("Seguimiento Universidad de Navarra") prospective cohort, our research group was pioneer in reporting that a better adherence to the Mediterranean diet was associated with a lower risk of COVID-19 among not health professionals (34). Thereafter, several studies conducted in other countries reported similar results $(4,32$, 39). The effect that we previously reported assessed only the overall dietary pattern (not each specific component of the Mediterranean diet) and only the risk of acquiring the infection, not its severity. Thus, the objective of the present study is to analyze the effect of each of the components of the Mediterranean Diet and some other specific foods on COVID-19 infection and also on its severity.

\section{MATERIALS AND METHODS}

\section{Study Sample}

The SUN Project is a prospective and multipurpose cohort study designed to evaluate different aspects of the Mediterranean dietary pattern and lifestyles, relating them to health outcomes.
By the end of 2019 it already had nearly 23,000 participants, who are evaluated every 2 years through self-administered questionnaires. It is a dynamic cohort, and so, although the recruitment started in 1999, it is permanently open. Participants are university graduates from many different universities all over Spain. The methods and more specific details of the SUN cohort have already been described previously (40).

In addition to the biennial questionnaires, from March to December 2020, a specific questionnaire on COVID-19 was sent to all participants. In this questionnaire they were asked whether or not they had undergone a diagnostic test for COVID-19, they were also asked about a medical diagnosis of the disease and about different related symptoms. For all this information they were also asked to record the corresponding dates.

Given the high COVID-19 pandemic burden in Spain during 2020 and that the most relevant exposures for healthcare professionals are related to their work in clinical care and not so much to nutritional factors, our main analyses focused on those participants who were not healthcare professionals, although the analysis for the total number of participants was also included. This decision was based on consideration of the highly relevant differences in exposures between both types of participants in our cohort.

\section{Outcome Measurement}

Two definitions to assess COVID-19 risk were used. One, more specific, included as incident cases only those participants who reported a positive diagnostic test. However, especially during the first months of the pandemic, there was a large under-diagnosis of the disease in Spain (41); consequently, not all cases were detected, potentially leaving a large number of false negatives. For a broader definition, participants with a medical diagnosis were also included as were those classified as incident cases by the Menni C. algorithm based on symptoms, age, and sex (42).

COVID-19 severity was also evaluated using two definitions. Those cases of COVID-19 that required hospitalization with symptoms compatible with the disease were classified as severe cases. Given the small number of participants with these characteristics, symptomatic cases were included in the severity analysis, and so symptomatic COVID-19 was included as a new outcome in our analysis. The symptoms included in this new definition were: cough, cold, respiratory distress, loss of smell or taste, diarrhea, and fever.

\section{Dietary Assessment}

For dietary assessment, data were taken from a previously validated semiquantitative food frequency questionnaire (FFQ) (43). It consists of 136 items with consumption grouped in nine categories from "never or almost never" to " $\geq 6$ times a day." From these data information on the consumption of different nutrients can also be obtained using data from updated Food Composition Tables (44).

This questionnaire is assessed at baseline and at 10 years of follow-up. Cumulative measures were used in those for whom information was available at both times.

The Mediterranean diet score (MDS) proposed by Trichopoulou was used to assess adherence to the Mediterranean 
diet. This index has been most widely used to assess adherence to the Mediterranean diet (45). The MDS considers nine components of the diet, 1 point corresponds to moderate ethanol intake (5-25 g/d for women and 10-50 g/d for men) and another point to the monounsaturated-to-saturated fatty acids ratio, the point is given to those with a ratio of monounsaturated to saturated fats at or above the sex-specific median. The other 7 points are for food groups: 1 point is given to those who have a consumption equal or higher than the sex-specific median consumption on each beneficial food groups (cereals, fruits and nuts, vegetables, legumes, and fish), or below the sex-specific median for two food groups that are not typical of the Mediterranean diet (meat and whole dairy products). The final punctuation ranges from 0 to 9 .

Second, for evaluating each food separately, to minimize confounding by total energy intake, residuals based on total energy intake were calculated. As the ratio of monounsaturated to saturated fats did not correspond to a specific food, it was replaced with olive oil consumption. This approximation was adopted since olive oil was the main source of monounsaturated fatty acids in the traditional Mediterranean diet (45).

\section{Other Covariates}

At baseline, standardized questionnaires were used for gathering information on demographic characteristics (age, sex, years of university education, occupation, and marital status), lifestyle habits (smoking status and physical activity) and anthropometric and clinical data (weight, height, and comorbidities).

This information was updated with different follow-up questionnaires. The diagnosis of new diseases and weight are updated in each of the follow-up questionnaires. Other variables, however, were updated less frequently, such as marital status (questionnaire after 14-year follow-up) or height (questionnaire after 10-year follow-up). For each of them the most recent available information was used.

\section{Statistical Analysis}

First, a description of the different variables with different statistical parameters was carried out. For categorical variables, the percentage of participants included in each group was calculated, and for numerical variables the mean and standard deviation were calculated, or the median and the interquartile range were calculated if the distribution of the variable did not follow a normal distribution.

Secondly, to evaluate the possible effect of the adherence to the Mediterranean diet and its components on the incidence and severity of COVID-19, multivariable adjusted logistic regression models were used. The odds ratio (OR) for COVID19 incidence was calculated according to both definitions established, symptomatic COVID-19 and severe COVID-19. For the Mediterranean diet a high adherence group $(7 \leq \mathrm{MDS} \leq$ 9) and an intermediate adherence group $(4 \leq \mathrm{MDS} \leq 6)$ were compared with a low adherence $(\mathrm{MDS}<4)$, used as reference.

For the different dietary components, the most extreme consumption categories were also compared. To do this, the energy-adjusted consumption of the different foods was divided into quintiles: the first quintile would correspond to the lowest consumption and the last to the highest consumption, with the other categories corresponding to intermediate levels of consumption.

The lowest consumption category was used as the reference category to evaluate foods typical of the Mediterranean diet (olive oil, fruits and nuts, vegetables, cereals, legumes, and fish). For foods that correspond to a negative score in the MDS, such as meat and whole dairy products, we used high consumption as the reference category. In addition, the effect of red meat and yogurt was also analyzed.

All ORs are expressed with their 95\% confidence intervals. Participants below the percentile 1 or above the percentile 99 of total energy intake were excluded from the analysis.

All analyses were carried out both excluding and including healthcare professionals (HP), namely doctors and nurses. STATA program (version 16) was used for data analysis.

\section{RESULTS}

By mid-2021 the COVID-19 questionnaire of the SUN cohort had been answered by 9,699 participants. However, 73 of them did not coincide with a participant in the SUN Project database, so the final number of subjects initially included in this study was 9,626. After excluding participants with total energy intake beyond percentiles 1 and 99, the study sample included 9,485 participants.

Baseline characteristics of the population included in the study are shown in Table 1. It is a middle-aged population (mean age $=$ 52.9 years), with a higher proportion of women, mostly married. Nearly one third of participants were doctors or nurses (32.5\%), a very similar proportion of the total population of the SUN cohort. Regarding lifestyles, half of the participants had never smoked. A description of the most important conditions and chronic diseases potentially related to the risk of COVID-19 is also shown in Table $\mathbf{1 .}$

There were no significant differences in these characteristics when HP were excluded. However, we observed 373 (3.9\%) cases of COVID-19 detected by a specific test for all our study population, but only $167(2.6 \%)$ of them were among non-healthcare professionals. When we added those cases with clinical diagnosis and the ones predicted by the algorithm, the difference decreased: we had $666(7 \%)$ for the total population and $382(6 \%)$ for non-healthcare professionals. The percentages were even closer for the symptomatic cases, with $565(6 \%)$ for all the study population and 338 (5.3\%) when we excluded doctors and nurses. Finally, for serious cases, the percentages were the same, having $35(0.4 \%)$ and $24(0.4 \%)$ cases, respectively. When we assessed the interaction between adherence to the Mediterranean diet and being a healthcare professional, we found only a marginally significant $p$ for interaction $(p=0.059)$ for test-diagnosed COVID-19 infection.

In Table 2, we describe the consumption of the different foods analyzed. We show the median consumption for each category after adding each participant's residual consumption to the average consumption. 
TABLE 1 | Baseline characteristics of the SUN cohort participants who completed the COVID-19 specific questionnaire.

\begin{tabular}{|c|c|c|}
\hline & $\begin{array}{c}\text { All } \\
(N=9,485)\end{array}$ & $\begin{array}{c}\text { Excluding HP } \\
(N=6,406)\end{array}$ \\
\hline \multicolumn{3}{|l|}{ Demographic characteristics } \\
\hline Age (years), mean (SD) & $52.9(12.0)$ & $52.8(12.1)$ \\
\hline Sex (female) (\%) & 62.3 & 59.1 \\
\hline Years of university education, median (IQR) & $5(4-5)$ & $5(4-5)$ \\
\hline \multicolumn{3}{|l|}{ Marital status (\%) } \\
\hline Single & 27.8 & 29.4 \\
\hline Married & 63.3 & 62.5 \\
\hline Divorced & 4.5 & 4.1 \\
\hline Others & 4.4 & 4.0 \\
\hline Healthcare professionals (\%) & 32.5 & - \\
\hline \multicolumn{3}{|l|}{ Lifestyle Habits } \\
\hline \multicolumn{3}{|l|}{ Smoking status (\%) } \\
\hline Current smoker & 20.5 & 21.3 \\
\hline Former smoker & 28.6 & 27.8 \\
\hline Physical activity (METS/week), median (IQR) & $14(5-27)$ & $13(5-27)$ \\
\hline \multicolumn{3}{|l|}{ Anthropometric and clinical data } \\
\hline Total energy intake (kcal/d), mean (SD) & $2,438(711)$ & $2,436(718)$ \\
\hline Adherence to the MDS (0-9 score), mean (SD) & $4.3(1.8)$ & $4.2(1.8)$ \\
\hline BMI $\left(\mathrm{kg} / \mathrm{m}^{2}\right)$, mean $(\mathrm{SD})$ & $24.3(3.9)$ & $24.3(3.9)$ \\
\hline Type 2-diabetes mellitus (\%) & 3.0 & 3.0 \\
\hline Hypertension (\%) & 21.0 & 21.3 \\
\hline Cardiovascular disease (\%) & 4.8 & 4.5 \\
\hline Cancer (\%) & 6.4 & 6.1 \\
\hline Pulmonary disease (\%) & 10.6 & 10.1 \\
\hline
\end{tabular}

HP, healthcare professionals; IQR, Interquartile Range; METS, Metabolic Equivalent Task; MDS, Mediterranean Diet Score; BMI, Body Mass Index.

Our main analysis is shown in Table 3. There, we displayed the odds ratio of COVID-19 infection for non-healthcare professionals. For the two COVID-19 definitions, we found a significant decrease in risk with greater adherence to the Mediterranean diet. For the highest adherence category, we found a $56 \%$ decrease in risk $(\mathrm{OR}=0.44$, 95\% CI: $0.22-$ $0.88, p$ for trend $=0.020$ ) when considering only cases with a positive test and $46 \%(\mathrm{OR}=0.64,95 \% \mathrm{CI}: 0.42-0.98, p$ for trend $=0.040$ ) when using the broader definition. Among the different foods, only yogurt and the consumption of whole dairy products showed a significant direct association. In whole dairy products, the lowest consumption category had a $45 \%$ decreased risk $(\mathrm{OR}=0.55,95 \% \mathrm{CI}: 0.33-0.94, p$ for trend $=$ 0.027 ) and a $35 \%$ decrease in the risk of COVID-19 (OR = $0.65,95 \%$ CI: $0.46-0.92$, $p$ for trend $=0.015$ ), as measured in test-positive cases and in all possible cases, respectively. The results for yogurt are consistent with these results, showing an $\mathrm{OR}=0.49(0.28-0.86)$ and an $\mathrm{OR}=0.71(0.50-1.03)$ for the low consumption category, respectively, as compared with the highest consumption, although this last result was no longer significant ( $p$ for trend $=0.068$ ).

For other foods, such as fish, although a point estimate for the OR was lower than the null value and a certain linear trend was
TABLE 2 | Median consumption of the foods analyzed across the different energy-adjusted quintiles of consumption of each food or food group.

\begin{tabular}{lccc}
\hline Food groups (g/day) & $\begin{array}{c}\text { Low } \\
\text { consumption } \\
\text { (Q1) }\end{array}$ & $\begin{array}{c}\text { Intermediate } \\
\text { consumption } \\
\text { (Q2-Q4) }\end{array}$ & $\begin{array}{c}\text { High } \\
\text { consumption } \\
\text { (Q5) }\end{array}$ \\
\hline Olive oil & 4 & 15 & 34 \\
Fruits and nuts & 79 & 297 & 640 \\
Vegetables & 139 & 323 & 605 \\
Cereals & 46 & 105 & 188 \\
Legumes & 10 & 21 & 35 \\
Fish & 41 & 90 & 163 \\
Meat & 98 & 173 & 261 \\
Red meat & 36 & 70 & 130 \\
Whole dairy products & 41 & 144 & 383 \\
Yogurt & 0 & 27 & 117
\end{tabular}

seen, the confidence intervals were wide and they included the null value and consequently, the $p$ for trend was not significant.

When we included healthcare professionals (see Table 4), the Mediterranean diet continued to have OR values below 1 for the point estimate, and with a linear trend, but the results were not significant. For COVID-19 cases with positive test, the only significant result was olive oil, with an OR $=1.53(1.07-2.18)$ for the high consumption category. The adverse association for meat consumption approached significance and achieved it when we extended the COVID-19 cases to all possible. This result would show a lower risk of COVID-19 for lower meat consumption $[\mathrm{OR}=0.76(0.58-0.99)]$. With this definition the result for whole dairy product was also close to being significant.

In Tables 5, 6, we evaluated the relationship between the Mediterranean diet and each of its particular components with the risk of symptomatic and severe COVID-19, both excluding and including healthcare professionals respectively.

When we excluded healthcare professionals, the inverse association of the Mediterranean diet with the risk of symptomatic COVID-19 showed a $p$ for trend $=0.050$. The effect of high adherence showed a protection of $66 \%$ [OR $=$ $0.64(0.41-1.00)]$ at the limit of statistical significance. Regarding its particular components, the only one with a detrimental association was again a low consumption of whole dairy products [OR $=0.69(0.48-1.00)$ for low vs. high consumption]. For serious COVID-19 cases, the inverse protective association with a high consumption of legumes deserves to be emphasized [OR $=0.21(0.04-0.98)$ for high vs. low consumption].

In Table 6, also adding health professionals we mainly found non-significant results for severe or symptomatic COVID-19.

\section{DISCUSSION}

As previously published by our research group (34), the Mediterranean Diet (MedDiet) showed a significant protective effect against COVID-19. In this work, we have further analyzed the effect of MedDiet on COVID-19, considering new definitions of the disease, as well as including severity as an outcome. This dietary pattern remained protective when apart from a 
TABLE 3 | Multivariable adjusted* odds ratios (OR) and 95\% confidence intervals (CI) of COVID-19 risk according to adherence to the Mediterranean diet (Mediterranean Diet Score, MDS) and consumption levels of different foods measured in residuals, excluding healthcare professionals.

\begin{tabular}{|c|c|c|c|c|c|c|c|}
\hline & & \multicolumn{3}{|c|}{ COVID-19 (positive test) } & \multicolumn{3}{|c|}{ COVID-19 ${ }^{\ddagger}$} \\
\hline & & $N$ cases $/ N$ total & OR (and $95 \% \mathrm{Cl}$ ) & $p$ for trend & $N$ cases $/ N$ total & OR (and 95\% Cl) & $p$ for trend \\
\hline \multirow[t]{3}{*}{ Mediterranean diet } & Low adherence & $76 / 2,347$ & 1 (Ref.) & 0.020 & $158 / 2,347$ & 1 (Ref.) & 0.040 \\
\hline & Intermediate adherence & $81 / 3,371$ & $0.73(0.52-1.01)$ & & $196 / 3,371$ & $0.87(0.70-1.09)$ & \\
\hline & High adherence & $10 / 688$ & $0.44(0.22-0.88)$ & & 28/688 & $0.64(0.42-0.98)$ & \\
\hline \multirow[t]{3}{*}{ Olive oil } & Low consumption (Q1) & $31 / 1,310$ & 1 (Ref.) & 0.980 & $74 / 1,310$ & 1 (Ref.) & 0.738 \\
\hline & Intermediate consumption (Q2-Q4) & $110 / 3,863$ & $1.36(0.90-2.08)$ & & 239/3,863 & $1.19(0.90-1.57)$ & \\
\hline & High consumption (Q5) & $26 / 1,233$ & $0.99(0.58-1.71)$ & & $69 / 1,233$ & $1.06(0.75-1.51)$ & \\
\hline \multirow[t]{3}{*}{ Fruits and nuts } & Low consumption (Q1) & $43 / 1,336$ & 1 (Ref.) & 0.381 & $90 / 1,336$ & 1 (Ref.) & 0.962 \\
\hline & Intermediate consumption (Q2-Q4) & $98 / 3,841$ & $0.88(0.59-1.31)$ & & $222 / 3,841$ & $0.93(0.70-1.22)$ & \\
\hline & High consumption (Q5) & $26 / 1,229$ & $0.78(0.45-1.35)$ & & $70 / 1,229$ & $0.99(0.69-1.42)$ & \\
\hline \multirow[t]{3}{*}{ Vegetables } & Low consumption (Q1) & $43 / 1,315$ & 1 (Ref.) & 0.963 & $84 / 1,315$ & 1 (Ref.) & 0.749 \\
\hline & Intermediate consumption (Q2-Q4) & $92 / 3,886$ & $0.80(0.54-1.18)$ & & $228 / 3,886$ & $1.01(0.76-1.33)$ & \\
\hline & High consumption (Q5) & $32 / 1,205$ & $1.01(0.61-1.68)$ & & $70 / 1,205$ & $1.06(0.74-1.51)$ & \\
\hline \multirow[t]{3}{*}{ Cereals } & Low consumption (Q1) & $40 / 1,279$ & 1 (Ref.) & 0.268 & $79 / 1,279$ & 1 (Ref.) & 0.590 \\
\hline & Intermediate consumption (Q2-Q4) & $99 / 3,848$ & $0.83(0.57-1.23)$ & & $237 / 3,848$ & $1.06(0.80-1.39)$ & \\
\hline & High consumption (Q5) & $28 / 1,279$ & $0.75(0.45-1.25)$ & & $66 / 1,279$ & $0.91(0.64-1.29)$ & \\
\hline \multirow[t]{3}{*}{ Legumes } & Low consumption (Q1) & $39 / 1,353$ & 1 (Ref.) & 0.987 & $86 / 1,353$ & 1 (Ref.) & 0.799 \\
\hline & Intermediate consumption (Q2-Q4) & $95 / 3,816$ & $0.90(0.61-1.32)$ & & $223 / 3,816$ & $0.95(0.72-1.23)$ & \\
\hline & High consumption (Q5) & $33 / 1,237$ & $1.00(0.62-1.63)$ & & $73 / 1,237$ & $0.96(0.69-1.33)$ & \\
\hline \multirow[t]{3}{*}{ Fish } & Low consumption (Q1) & $42 / 1,348$ & 1 (Ref.) & 0.118 & $93 / 1,348$ & 1 (Ref.) & 0.062 \\
\hline & Intermediate consumption (Q2-Q4) & $101 / 3,827$ & $0.88(0.60-1.29)$ & & $231 / 3,827$ & $0.90(0.69-1.17)$ & \\
\hline & High consumption (Q5) & $24 / 1,231$ & $0.65(0.38-1.12)$ & & $58 / 1,231$ & $0.71(0.50-1.02)$ & \\
\hline \multirow[t]{3}{*}{ Meat } & High $^{\star \star \star}$ consumption & $35 / 1,281$ & 1 (Ref.) & 0.323 & $87 / 1,281$ & 1 (Ref.) & 0.536 \\
\hline & Intermediate consumption (Q2-Q4) & $109 / 3,855$ & $1.14(0.77-1.70)$ & & $225 / 3,855$ & $0.90(0.69-1.18)$ & \\
\hline & Low consumption (Q1) & $23 / 1,270$ & $0.76(0.43-1.32)$ & & $70 / 1,270$ & $0.90(0.64-1.26)$ & \\
\hline \multirow[t]{3}{*}{ Red meat** } & High $^{\star \star \star}$ consumption & $43 / 1,289$ & 1 (Ref.) & 0.415 & $81 / 1,289$ & 1 (Ref.) & 0.998 \\
\hline & Intermediate consumption (Q2-Q4) & $93 / 3,845$ & $0.76(0.52-1.11)$ & & $226 / 3,845$ & $0.96(0.73-1.25)$ & \\
\hline & Low consumption (Q1) & $31 / 1,272$ & $0.82(0.50-1.33)$ & & $75 / 1,272$ & $1.00(0.71-1.40)$ & \\
\hline \multirow[t]{3}{*}{ Whole dairy products } & High $^{\star \star \star}$ consumption & 49/1,309 & 1 (Ref.) & 0.027 & $104 / 1,309$ & 1 (Ref.) & 0.015 \\
\hline & Intermediate consumption (Q2-Q4) & $94 / 3,868$ & $0.67(0.47-0.98)$ & & $213 / 3,868$ & $0.67(0.52-0.86)$ & \\
\hline & Low consumption (Q1) & $24 / 1,229$ & $0.55(0.33-0.94)$ & & $65 / 1,229$ & $0.65(0.46-0.92)$ & \\
\hline \multirow[t]{3}{*}{ Yogurt** } & High $^{\star \star \star}$ consumption & $42 / 1,289$ & 1 (Ref.) & 0.013 & $81 / 1,289$ & 1 (Ref.) & 0.068 \\
\hline & Intermediate consumption (Q2-Q4) & $106 / 3,897$ & $0.87(0.60-1.26)$ & & $245 / 3,897$ & $1.01(0.77-1.31)$ & \\
\hline & Low consumption (Q1) & $19 / 1,220$ & $0.49(0.28-0.86)$ & & $56 / 1,220$ & $0.71(0.50-1.03)$ & \\
\hline \multirow[t]{2}{*}{ Alcoholv* } & Not moderate consumption & $109 / 4,364$ & 1 (Ref.) & & $267 / 4,364$ & 1 (Ref.) & \\
\hline & Moderate consumption & $58 / 2,042$ & $1.20(0.86-1.68)$ & 0.290 & $115 / 2,042$ & $0.95(0.75-1.20)$ & 0.641 \\
\hline
\end{tabular}

${ }^{*}$ Adjusted for sex, age, years of university studies, marital status, smoking, BMI, physical activity at leisure-time, year of entering the cohort, previous diagnosis of chronic diseases (diabetes, hypertension, cardiovascular disease, cancer or pulmonary disease) and category of consumption of the other food groups.

${ }^{*} / n$ the adjustment for the calculation of the ORs of red meat and yogurt, the total consumption of meat and whole dairy products, respectively, had not been included in the model.

${ }^{* \star *}$ For foods that are not typical of the Mediterranean diet (meat, red meat, whole dairy products and yogurt), the reference category was changed to the highest consumption category. ${ }^{v}$ With respect to alcohol, moderate vs. non-moderate consumption was compared. Therefore, the $p$-value is not a $p$ for trend.

¥This definition of COVID-19 includes participants with a positive test and medical diagnosis, as well as those classified as incident cases by the Menni C. algorithm based on symptoms, age, and sex.

COVID-19 positive test, symptoms, and medical-diagnosis were also included, and a linear trend was observed. For severe COVID-19 the incidence was very low, so no significant results were found (there was only one case of severe COVID-19 among participants with high MedDiet adherence).

Mediterranean Diet has been mainly characterized by having antiinflammatory properties, intestinal microbiota modulation, and immune protective effect, which may protect against COVID-19 $(16,23)$, in addition, its benefits have been attributed to these characteristics also for many non-communicable diseases (46). However, when the effect on COVID-19 incidence has been analyzed for individual foods, overall, significant associations have been scarcely found.

Among the different food groups included in the MDS defined by Trichopoulou (45), the only result that can be highlighted is the detrimental effect of whole dairy products. A significant linear association was found between a low consumption of whole dairy products and lower risk of COVID-19 positive test as well as 
TABLE 4 | Multivariable adjusted* odds ratios (OR) and 95\% confidence intervals (CI) of COVID-19 risk according to adherence to the Mediterranean diet (Mediterranean Diet Score, MDS) and consumption levels of different foods measured in residuals, including healthcare professionals.

\begin{tabular}{|c|c|c|c|c|c|c|c|}
\hline & & \multicolumn{3}{|c|}{ COVID-19 (positive test) } & \multicolumn{3}{|c|}{ COVID-19 ${ }^{\ddagger}$} \\
\hline & & $N$ cases $/ N$ total & OR (and $95 \% \mathrm{Cl}$ ) & $p$ for trend & $N$ cases $/ N$ total & OR (and 95\% Cl) & $p$ for trend \\
\hline \multirow[t]{3}{*}{ Mediterranean diet } & Low adherence & $142 / 3,300$ & 1 (Ref.) & 0.166 & $248 / 3,300$ & 1 (Ref.) & 0.137 \\
\hline & Intermediate adherence & $199 / 5,082$ & $0.94(0.75-1.18)$ & & $360 / 5,082$ & $0.98(0.83-1.17)$ & \\
\hline & High adherence & $32 / 1,103$ & $0.75(0.49-1.13)$ & & $58 / 1,103$ & $0.79(0.58-1.08)$ & \\
\hline \multirow[t]{3}{*}{ Olive oil } & Low consumption (Q1) & $58 / 1,898$ & 1 (Ref.) & 0.020 & $118 / 1,898$ & 1 (Ref.) & 0.099 \\
\hline & Intermediate consumption (Q2-Q4) & $234 / 5,692$ & $1.47(1.09-1.99)$ & & $412 / 5,692$ & $1.26(1.01-1.56)$ & \\
\hline & High consumption (Q5) & $81 / 1,895$ & $1.53(1.07-2.18)$ & & $136 / 1,895$ & $1.25(0.96-1.63)$ & \\
\hline \multirow[t]{3}{*}{ Fruits and nuts } & Low consumption (Q1) & 78/1,899 & 1 (Ref.) & 0.108 & $142 / 1,899$ & 1 (Ref.) & 0.250 \\
\hline & Intermediate consumption (Q2-Q4) & $243 / 5,690$ & $1.14(0.86-1.50)$ & & $409 / 5,690$ & $1.04(0.84-1.29)$ & \\
\hline & High consumption (Q5) & $52 / 1,896$ & $0.76(0.52-1.12)$ & & $115 / 1,896$ & $0.94(0.71-1.25)$ & \\
\hline \multirow[t]{3}{*}{ Vegetables } & Low consumption (Q1) & $72 / 1,898$ & 1 (Ref.) & 0.166 & $128 / 1,898$ & 1 (Ref.) & 0.684 \\
\hline & Intermediate consumption (Q2-Q4) & $230 / 5,691$ & $1.13(0.84-1.51)$ & & $410 / 5,691$ & $1.15(0.93-1.44)$ & \\
\hline & High consumption (Q5) & $71 / 1,896$ & $1.11(0.77-1.60)$ & & $128 / 1,896$ & $1.13(0.86-1.49)$ & \\
\hline \multirow[t]{3}{*}{ Cereals } & Low consumption (Q1) & $86 / 1,898$ & 1 (Ref.) & 0.559 & $147 / 1,898$ & 1 (Ref.) & 0.371 \\
\hline & Intermediate consumption (Q2-Q4) & $224 / 5,691$ & $0.83(0.64-1.08)$ & & $400 / 5,691$ & $0.91(0.74-1.11)$ & \\
\hline & High consumption (Q5) & $63 / 1,896$ & $0.75(0.53-1.06)$ & & 119/1,896 & $0.86(0.66-1.11)$ & \\
\hline \multirow[t]{3}{*}{ Legumes } & Low consumption (Q1) & $76 / 1,898$ & 1 (Ref.) & 0.683 & $143 / 1,898$ & 1 (Ref.) & 0.600 \\
\hline & Intermediate consumption (Q2-Q4) & $215 / 5,691$ & $0.91(0.69-1.20)$ & & $387 / 5,691$ & $0.88(0.72-1.09)$ & \\
\hline & High consumption (Q5) & $82 / 1,896$ & $1.07(0.77-1.49)$ & & $136 / 1,896$ & $0.93(0.73-1.20)$ & \\
\hline \multirow[t]{3}{*}{ Fish } & Low consumption (Q1) & $92 / 1,898$ & 1 (Ref.) & 0.108 & $156 / 1,898$ & 1 (Ref.) & 0.144 \\
\hline & Intermediate consumption (Q2-Q4) & $208 / 5,691$ & $0.68(0.52-0.89)$ & & $383 / 5,691$ & $0.79(0.64-0.97)$ & \\
\hline & High consumption (Q5) & $73 / 1,896$ & $0.76(0.54-1.06)$ & & $127 / 1,896$ & $0.82(0.63-1.07)$ & \\
\hline \multirow[t]{3}{*}{ Meat } & High $^{\star \star \star}$ consumption & $82 / 1,896$ & 1 (Ref.) & 0.057 & $153 / 1,896$ & 1 (Ref.) & 0.045 \\
\hline & Intermediate consumption (Q2-Q4) & $243 / 5,691$ & $1.09(0.84-1.43)$ & & $410 / 5,691$ & $0.96(0.78-1.17)$ & \\
\hline & Low consumption (Q1) & $48 / 1,898$ & $0.69(0.47-1.01)$ & & $103 / 1,898$ & $0.76(0.58-0.99)$ & \\
\hline \multirow[t]{3}{*}{ Red meat** } & High $^{\star \star \star}$ consumption & $91 / 1,896$ & 1 (Ref.) & 0.268 & $91 / 1,896$ & 1 (Ref.) & 0.392 \\
\hline & Intermediate consumption (Q2-Q4) & $211 / 5,691$ & $0.78(0.60-1.01)$ & & $211 / 5,691$ & $0.97(0.79-1.18)$ & \\
\hline & Low consumption (Q1) & $71 / 1,898$ & $0.83(0.60-1.15)$ & & $71 / 1,898$ & $0.89(0.69-1.16)$ & \\
\hline \multirow[t]{3}{*}{ Whole dairy products } & High $^{\star \star \star}$ consumption & $84 / 1,896$ & 1 (Ref.) & 0.386 & $154 / 1,896$ & 1 (Ref.) & 0.059 \\
\hline & Intermediate consumption (Q2-Q4) & $223 / 5,691$ & $0.89(0.68-1.17)$ & & $395 / 5,691$ & $0.84(0.68-1.03)$ & \\
\hline & Low consumption (Q1) & $66 / 1,898$ & $0.86(0.60-1.22)$ & & $117 / 1,898$ & $0.77(0.59-1.01)$ & \\
\hline \multirow[t]{3}{*}{ Yogurt** } & High $^{\star \star \star}$ consumption & $83 / 1,896$ & 1 (Ref.) & 0.307 & $83 / 1,896$ & 1 (Ref.) & 0.152 \\
\hline & Intermediate consumption (Q2-Q4) & $226 / 5,691$ & $0.93(0.71-1.21)$ & & $226 / 5,691$ & $1.04(0.85-1.28)$ & \\
\hline & Low consumption (Q1) & $64 / 1,898$ & $0.83(0.59-1.18)$ & & $64 / 1,898$ & $0.82(0.63-1.08)$ & \\
\hline \multirow[t]{2}{*}{ Alcoholv* } & Not moderate consumption & $259 / 6,542$ & 1 (Ref.) & & $472 / 6,542$ & 1 (Ref.) & \\
\hline & Moderate consumption & $114 / 2,943$ & $1.13(0.89-1.43)$ & 0.305 & $194 / 2,943$ & $0.99(0.83-1.19)$ & 0.937 \\
\hline
\end{tabular}

${ }^{*}$ Adjusted for sex, age, years of university studies, marital status, smoking, BMI, physical activity at leisure-time, year of entering the cohort, previous diagnosis of chronic diseases (diabetes, hypertension, cardiovascular disease, cancer or pulmonary disease) and category of consumption of the other food groups.

${ }^{*} / n$ the adjustment for the calculation of the ORs of red meat and yogurt, the total consumption of meat and whole dairy products, respectively, had not been included in the model.

${ }^{* \star *}$ For foods that are not typical of the Mediterranean diet (meat, red meat, whole dairy products and yogurt), the reference category was changed to the highest consumption category. ${ }^{v}$ With respect to alcohol, moderate vs. non-moderate consumption was compared. Therefore, the $p$-value is not a $p$ for trend.

¥This definition of COVID-19 includes participants with a positive test and medical diagnosis, as well as those classified as incident cases by the Menni C. algorithm based on symptoms, age, and sex.

symptomatic COVID-19. Likewise, consumption of yogurt was directly associated with the risk of having a positive COVID-19 test, and a linear trend was found for this association.

There is scarce evidence on these associations. The effect of dairy on COVID-19 is greatly focused on fermented dairy products, mainly on those including probiotics, which is not consistent with our results, and are associated with an enhanced immunity and lower risk of infectious diseases, including COVID-19 (mainly based on the modulation of intestinal microbiome) $(15,16,30,35,47,48)$. Similarly, there is evidence on the immune modulatory role of raw cow's milk on respiratory infections (49), and even a recent publication has also shown activity against SARS-CoV-2 of some milkderived bioactive peptides $(47,50)$. However, there are also publications that describe mechanisms that could explain the association found in this work. For instance, some authors have described the possibility of having acquired SARS-CoV-2 through contamination by dairy products $(51,52)$. 
TABLE 5 | Multivariable adjusted* odds ratios (OR) and 95\% confidence intervals (CI) of symptomatic and severe COVID-19 risk according to adherence to the Mediterranean diet (Mediterranean Diet Score, MDS) and consumption levels of different foods measured in residuals, excluding healthcare professionals.

\begin{tabular}{|c|c|c|c|c|c|c|c|}
\hline & & \multicolumn{3}{|c|}{ Symptomatic COVID-19 } & \multicolumn{3}{|c|}{ Serious COVID-19 } \\
\hline & & $N$ cases $/ N$ total & OR (and 95\% Cl) & $p$ for trend & $N$ cases $/ N$ total & OR (and $95 \% \mathrm{Cl}$ ) & $p$ for trend \\
\hline \multirow[t]{3}{*}{ Mediterranean diet } & Low adherence & $143 / 2,347$ & 1 (Ref.) & 0.050 & $7 / 2,347$ & 1 (Ref.) & 0.270 \\
\hline & Intermediate adherence & $169 / 3,371$ & $0.82(0.65-1.04)$ & & $16 / 3,371$ & $1.28(0.51-3.24)$ & \\
\hline & High adherence & 26/688 & $0.64(0.41-1.00)$ & & $1 / 688$ & $0.30(0.03-2.57)$ & \\
\hline \multirow[t]{3}{*}{ Olive oil } & Low consumption (Q1) & $70 / 1,310$ & 1 (Ref.) & 0.714 & $7 / 1,310$ & 1 (Ref.) & 0.619 \\
\hline & Intermediate consumption (Q2-Q4) & $210 / 3,863$ & $1.10(0.82-1.47)$ & & $12 / 3,863$ & $0.57(0.21-1.55)$ & \\
\hline & High consumption (Q5) & $58 / 1,233$ & $0.93(0.65-1.35)$ & & $5 / 1,233$ & $0.74(0.22-2.45)$ & \\
\hline \multirow[t]{3}{*}{ Fruits and nuts } & Low consumption (Q1) & $81 / 1,336$ & 1 (Ref.) & 0.798 & $5 / 1,336$ & 1 (Ref.) & 0.090 \\
\hline & Intermediate consumption (Q2-Q4) & $192 / 3,841$ & $0.90(0.68-1.21)$ & & $12 / 3,841$ & $1.30(0.42-4.03)$ & \\
\hline & High consumption (Q5) & $65 / 1,229$ & $1.05(0.72-1.52)$ & & $7 / 1,229$ & $3.17(0.83-12.08)$ & \\
\hline \multirow[t]{3}{*}{ Vegetables } & Low consumption (Q1) & $75 / 1,315$ & 1 (Ref.) & 0.519 & $8 / 1,315$ & 1 (Ref.) & 0.144 \\
\hline & Intermediate consumption (Q2-Q4) & $209 / 3,886$ & $1.05(0.78-1.40)$ & & $13 / 3,886$ & $0.52(0.20-1.37)$ & \\
\hline & High consumption (Q5) & $54 / 1,205$ & $0.88(0.60-1.30)$ & & $3 / 1,205$ & $0.34(0.08-1.45)$ & \\
\hline \multirow[t]{3}{*}{ Cereals } & Low consumption (Q1) & $73 / 1,279$ & 1 (Ref.) & 0.534 & $5 / 1,279$ & 1 (Ref.) & 0.627 \\
\hline & Intermediate consumption (Q2-Q4) & $205 / 3,848$ & $0.99(0.74-1.32)$ & & $13 / 3,848$ & $1.08(0.36-3.19)$ & \\
\hline & High consumption (Q5) & $60 / 1,279$ & $0.89(0.62-1.28)$ & & $6 / 1,279$ & $1.37(0.38-4.91)$ & \\
\hline \multirow[t]{3}{*}{ Legumes } & Low consumption (Q1) & $78 / 1,353$ & 1 (Ref.) & 0.470 & $11 / 1,353$ & 1 (Ref.) & 0.047 \\
\hline & Intermediate consumption (Q2-Q4) & $199 / 3,816$ & $0.94(0.71-1.24)$ & & $11 / 3,816$ & $0.37(0.15-0.90)$ & \\
\hline & High consumption (Q5) & $61 / 1,237$ & $0.88(0.62-1.25)$ & & $2 / 1,237$ & $0.21(0.04-0.98)$ & \\
\hline \multirow[t]{3}{*}{ Fish } & Low consumption (Q1) & $82 / 1,348$ & 1 (Ref.) & 0.155 & $6 / 1,348$ & 1 (Ref.) & 0.939 \\
\hline & Intermediate consumption (Q2-Q4) & $203 / 3,827$ & $0.92(0.69-1.21)$ & & $14 / 3,827$ & 0.99 (0.36-2.73) & \\
\hline & High consumption (Q5) & $53 / 1,231$ & $0.76(0.52-1.11)$ & & $4 / 1,231$ & $0.95(0.24-3.76)$ & \\
\hline \multirow[t]{3}{*}{ Meat } & High $^{\star \star \star}$ consumption & $82 / 1,281$ & 1 (Ref.) & 0.563 & $5 / 1,281$ & 1 (Ref.) & 0.628 \\
\hline & Intermediate consumption (Q2-Q4) & $191 / 3,855$ & $0.82(0.62-1.08)$ & & $14 / 3,855$ & $0.96(0.33-2.83)$ & \\
\hline & Low consumption (Q1) & $65 / 1,270$ & $0.90(0.63-1.28)$ & & $5 / 1,270$ & $0.72(0.19-2.74)$ & \\
\hline \multirow[t]{3}{*}{ Red meat ${ }^{\star \star}$} & High $^{\star \star *}$ consumption & $68 / 1,289$ & 1 (Ref.) & 0.744 & $5 / 1,289$ & 1 (Ref.) & 0.721 \\
\hline & Intermediate consumption (Q2-Q4) & $204 / 3,845$ & $1.04(0.78-1.39)$ & & $14 / 3,845$ & $0.98(0.34-2.84)$ & \\
\hline & Low consumption (Q1) & $66 / 1,272$ & $1.06(0.74-1.53)$ & & $5 / 1,272$ & $0.79(0.21-2.94)$ & \\
\hline \multirow[t]{3}{*}{ Whole dairy products } & High $^{\star \star \star}$ consumption & $89 / 1,309$ & 1 (Ref.) & 0.049 & $7 / 1,309$ & 1 (Ref.) & 0.190 \\
\hline & Intermediate consumption (Q2-Q4) & $190 / 3,868$ & $0.71(0.54-0.93)$ & & $13 / 3,868$ & $0.59(0.22-1.57)$ & \\
\hline & Low consumption (Q1) & $59 / 1,229$ & $0.69(0.48-1.00)$ & & $4 / 1,229$ & $0.41(0.11-1.56)$ & \\
\hline \multirow[t]{3}{*}{ Yogurt** } & High $^{\star \star \star}$ consumption & $68 / 1,289$ & 1 (Ref.) & 0.307 & $6 / 1,289$ & 1 (Ref.) & 0.197 \\
\hline & Intermediate consumption (Q2-Q4) & $216 / 3,897$ & $1.07(0.80-1.43)$ & & $15 / 3,897$ & $0.86(0.32-2.34)$ & \\
\hline & Low consumption (Q1) & $54 / 1,220$ & $0.82(0.56-1.20)$ & & $3 / 1,220$ & $0.38(0.09-1.64)$ & \\
\hline \multirow[t]{2}{*}{ Alcohol $^{\vee *}$} & Not moderate consumption & $235 / 4,364$ & 1 (Ref.) & & $15 / 4,364$ & 1 (Ref.) & \\
\hline & Moderate consumption & $103 / 2,042$ & $0.96(0.75-1.23)$ & 0.737 & $58 / 2,042$ & $1.17(0.49-2.80)$ & 0.716 \\
\hline
\end{tabular}

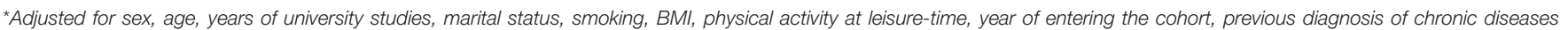
(diabetes, hypertension, cardiovascular disease, cancer or pulmonary disease) and category of consumption of the other food groups.

${ }^{*}$ In the adjustment for the calculation of the ORs of red meat and yogurt, the total consumption of meat and whole dairy products, respectively, had not been included in the model.

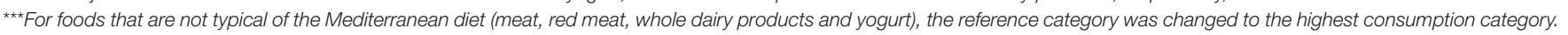

$\checkmark$ *With respect to alcohol, moderate vs. non-moderate consumption was compared. Therefore, the $p$-value is not a $p$ for trend.

Another study, although of ecological design, which analyzed the correlation between different foods and nutrients and COVID-19 infection and mortality worldwide, found that countries with higher calcium intake had higher infection rates (29). The authors also found an increased crude infection rate for increased consumption of milk. Spain is a country with a high incidence of COVID-19 and is also among the countries with the highest milk consumption worldwide (53), so this possible ecological explanation could be further analyzed.
Another related hypothesis, also recently described by Deschasaux-Tanguy et al. (54), could be due to the calcium content of dairy products. Different studies have shown a relation between calcium levels and COVID-19 $(55,56)$, although the mechanism of the causal relation is not clear yet. For other viruses, including SARS-CoV and MERS-CoV, calcium plays an important role in their infectiousness and replication (57-59). Likewise, a low consumption of dairy products and consequently, lower calcium levels could limit the entrance and replication of 
TABLE 6 | Multivariable adjusted* Odds ratios (OR) and 95\% confidence intervals (CI) of symptomatic and severe COVID-19 risk according to adherence to the Mediterranean diet (Mediterranean Diet Score, MDS) and consumption levels of different foods measured in residuals, including healthcare professionals.

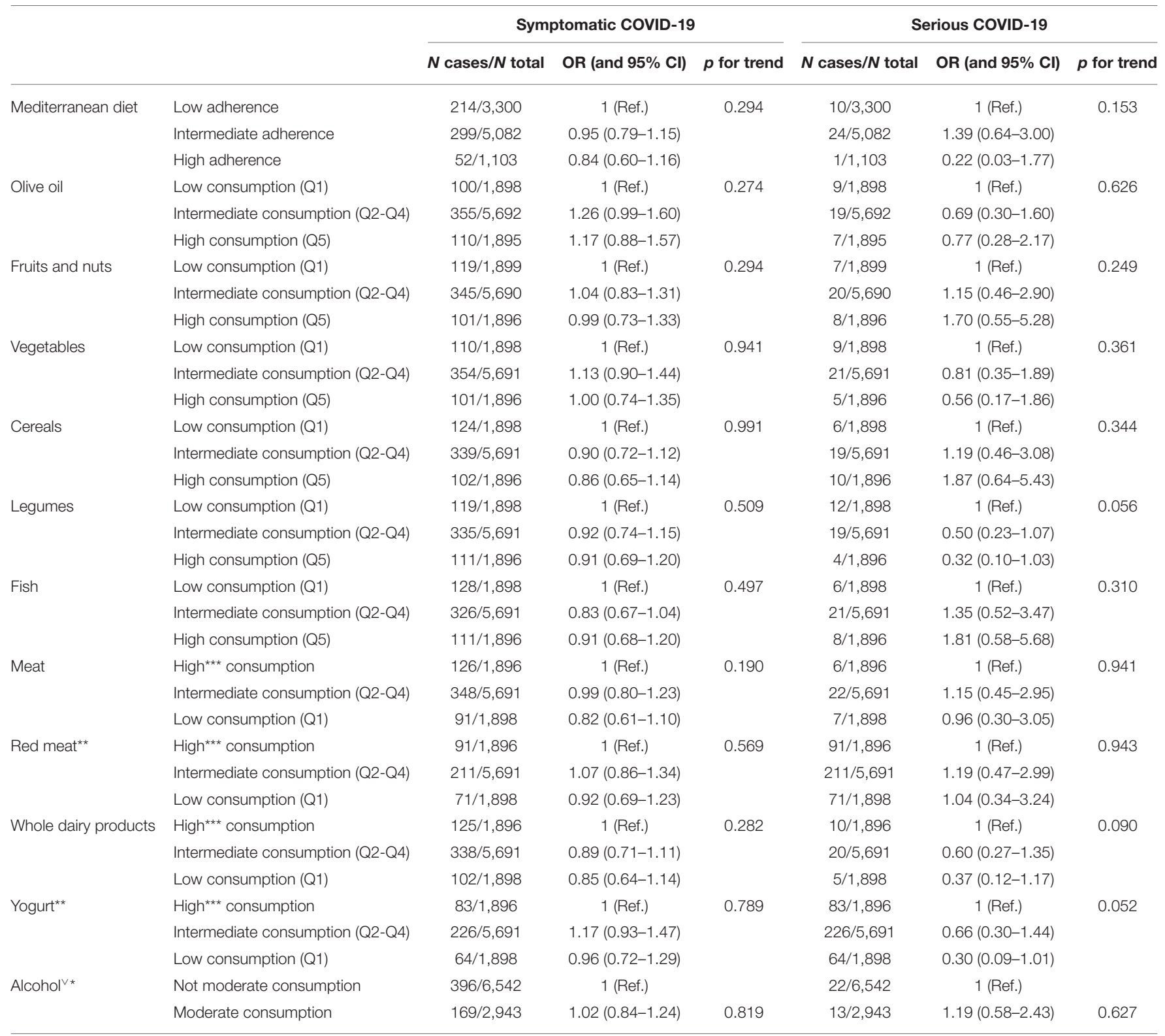

${ }^{*}$ Adjusted for sex, age, years of university studies, marital status, smoking, BMI, physical activity at leisure-time, year of entering the cohort, previous diagnosis of chronic diseases (diabetes, hypertension, cardiovascular disease, cancer or pulmonary disease) and category of consumption of the other food groups.

${ }^{*} / n$ the adjustment for the calculation of the ORs of red meat and yogurt, the total consumption of meat and whole dairy products, respectively, had not been included in the model.

${ }^{\star \star \star *}$ For foods that are not typical of the Mediterranean diet (meat, red meat, whole dairy products and yogurt), the reference category was changed to the highest consumption category.

${ }^{v}$ With respect to alcohol, moderate vs. non-moderate consumption was compared. Therefore, the $p$-value is not a $p$ for trend.

SARS-CoV-2. Also, a protective effect of vitamin D against SARSCoV-2 has been described as a result of its immunomodulatory properties on macrophages, monocytes, dendritic cells, and $\mathrm{T}$ and B lymphocytes $(60,61)$. As there is low consistent evidence on the association between dairy products and COVID-19, more plausible explanations, biological and nutritional mechanisms should be explored to explain this association. Apart from yogurt, the specific effect of other dairy products which have not been analyzed in this work should be studied in more detail; this could help understand the observed effect for dairies.

With respect to other food groups, for legumes, we found a significant protective effect, only for COVID-19 severity. However, as noted above, it is important to consider the low number of cases of severe COVID-19.

For the rest of the components, no effect was observed. For olive oil, despite its antioxidant and anti-inflammatory 
effect, no individual effect was seen. This could be partly explained by the fact that we do not collect the different types of olive oil and these effects are mainly found in extra virgin olive oil. This type of oil, which has a higher unsaponifiable fraction where the components (vitamins, polyphenols) that give extra virgin olive oil these properties, are found (33). The same unexpected results as for olive oil were found for vegetables and fruit and nuts. Our results are not consistent with those found by $\mathrm{Vu}$ and cols. who analyzed in the UK Biobank the association of different food groups and incident COVID-19. They showed that a higher consumption of vegetables was independently associated with lower odds of COVID-19, which could be explained by their antiinflammatory and antiviral properties (27). On the other hand, there are also studies that have shown a relationship between higher fruit consumption and SARS-CoV-2 infection (29).

Fish and cereals have protective ORs and "a certain linear trend"; however, their confidence intervals include the null value, and so the final results were not significant. Other authors also show no significant association for fish consumption and COVID-19 (27). Perhaps an effect might be expected because of their vitamin $\mathrm{D}$ or omega-3 fatty acid content, which has shown some effect on COVID19 as a result of their impact on the expression of proand antiinflammatory cytokines $(10,12,21,31,62-64)$. In this work, whether it was oily fish or not was not evaluated. Regarding cereals, an antiinflammatory effect related to their fiber fermentation by the gut microbiota has been described (23).

It should be noted that our results are focused on nonhealthcare participants. It has been considered that the general characteristics of this population were similar to those of non-healthcare workers and that healthcare personnel were at additional risk of COVID-19, especially at the time of the study, and that priority was given in this group to diagnostic testing $(65,66)$. This approach has been taken into account to overcome one of our major limitations, which is not having been able to measure several other exposures of the participants, according to the rigor of compliance with non-pharmacological preventive measures (masks, physical distancing, hand washing, and ventilation).

Finally, we can conclude that the effect of the complete Mediterranean dietary pattern is more important than that of its individual food groups. On one hand, for some foods, there was not a big difference between the most extreme consumption categories; therefore, the effect of high or low consumption would be more difficult to be observed. As more foods are included, these differences will grow. On the other hand, although we found a significant inverse association between dairy products and COVID-19, the effect of the Mediterranean diet is the combined effect of all its components, which can combine and enhance each other. Undoubtedly, the recommendation of a complete pattern is much more effective than that of isolated foods.

\section{DATA AVAILABILITY STATEMENT}

The original contributions presented in the study are included in the article/supplementary material, further inquiries can be directed to the corresponding author/s.

\section{ETHICS STATEMENT}

The studies involving human participants were reviewed and approved by the Research Ethics Committee of the University of Navarra. The patients/participants provided their written informed consent to participate in this study.

\section{AUTHOR CONTRIBUTIONS}

RP-A, MM-G, and SC participated in the design of the study. RP-A was involved in the data analysis, supervised by SC and MM-G. SC and RP-A participated in writing the original manuscript. Finally, the manuscript was reviewed by MM-G and AG. All authors contributed to the article and approved the submitted version.

\section{FUNDING}

The SUN Project has received funding from the Spanish Government-Instituto de Salud Carlos III, and the European Regional Development Fund (FEDER) (RD 06/0045, CIBEROBN, Grants PI10/02658, PI10/02293, PI13/00615, PI14/01668, PI14/01798, PI14/01764, PI17/01795, and G03/140), the Navarra Regional Government (27/2011, 45/2011, 122/2014), the Government Delegation for the National Drug Plan (2020/ 021), and the University of Navarra.

\section{ACKNOWLEDGMENTS}

We thank other members of the SUN group: AguileraBuenosvinos I, Alonso A, Álvarez-Álvarez I, Balaguer A, Barbagallo M, Barbería M, Barrientos I, Barrio-López MT, Basterra-Gortari FJ, Battezzati A, Bazal P, Benito S, Bertoli S, BesRastrollo M, Beulen Y, Beunza JJ, Buil-Cosiales P, Bullón-Vela V, Canales M, Carmona L, Cervantes S, Cristobo C, de Irala J, de la Fuente-Arrillaga C, de la O V, de la Rosa PA, Delgado-Rodríguez M, Díaz-Gutiérrez J, Díez Espino J, Domínguez L, Donat-Vargas C, Donazar M, Eguaras S, Fernández-Montero A, Fresán U, Galbete C, García-Arellano A, García López M, Gardeazábal I, GutiérrezBedmar M, Gomes-Domingos AL, Gómez-Donoso C, Gómez-Gracia E, Goñi E, Goñi L, Guillén F, Henríquez P, Hernández A, Hershey MS, Hidalgo-Santamaría M, Hu E, Lacarra C, Lahortiga F, Leone A, Llorca J, López del Burgo C, Marí A, Marques I, Martí A, Martín Calvo N, Martín-Moreno JM, Martínez JA, Martínez-Lapiscina EH, Mendonça R, Menéndez C, Molendijk M, Molero P, Murphy K, Muñoz M, Núñez Córdoba JM, Pajares R, Pano O, Papadaki A, Parletta N, Pérez de Ciriza P, Pérez Cornago A, Pérez de Rojas J, Pimenta AM, Pons J, Ramallal R, Razquin C, Rico-Campà A, Romanos-Nanclares A, 
Ruano C, Ruiz L, Ruiz-Canela M, Ruiz Zambrana A, Salgado E, San Julián B, Sánchez D, Sánchez-Bayona R, Sánchez-Tainta A, Sánchez-Villegas A, Santiago S, Sayón-Orea C, Schlatter J, Serrano-Martinez M, Toledo E, Toledo J, Tortosa A, Valencia F, Vázquez Z, Zarnowiecki D, Zazpe I. We thank very especially all participants in the SUN cohort for their long-standing and

\section{REFERENCES}

1. Dong E, Du H, Gardner L. Coronavirus COVID-19 (2019-nCoV). Available online at: https:/gisanddata.maps.arcgis.com/apps/dashboards/ bda7594740fd40299423467b48e9ecf6 (accessed October 28, 2021).

2. Centers for Disease Control Prevention. Scientific Brief: SARS-CoV-2 Transmission | CDC. Available online at: https://www.cdc.gov/coronavirus/ 2019-ncov/science/science-briefs/sars-cov-2-transmission.html (accessed October 28, 2021).

3. Cunningham JW, Vaduganathan $M$, Claggett BL, Jering KS, Bhatt AS, Rosenthal $\mathrm{N}$, et al. Clinical outcomes in young US adults hospitalized with COVID-19. JAMA Intern Med. (2021) 181:379-81. doi: 10.1001/jamainternmed.2020.5313

4. Merino J, Joshi AD, Nguyen LH, Leeming ER, Mazidi M, Drew DA, et al. Diet quality and risk and severity of COVID-19: a prospective cohort study. Gut. (2021) 70:2096-104. doi: 10.1136/gutjnl-2021-325353

5. Gleeson LE, Roche HM, Sheedy FJ. Obesity, COVID-19 and innate immunometabolism. $\mathrm{Br} J \quad$ Nutr. (2021) 125:628-32. doi: 10.1017/S0007114520003529

6. James PT, Ali Z, Armitage AE, Bonell A, Cerami C, Drakesmith H, et al. The role of nutrition in COVID-19 susceptibility and severity of disease: a systematic review. J Nutr. (2021) 151:1854-78. doi: 10.1093/jn/nxab059

7. Frates EP, Rifai T. Making the case for "COVID-19 prophylaxis" with lifestyle medicine. Am J Heal Promot. (2020) 34:689-91. doi: $10.1177 / 0890117120930536 \mathrm{c}$

8. Suardi C, Cazzaniga E, Graci S, Dongo D, Palestini P. Link between viral infections, immune system, inflammation and diet. Int J Environ Res Public Health. (2021) 18:1-13. doi: 10.3390/ijerph18052455

9. Detopoulou P, Demopoulos CA, Antonopoulou S. Micronutrients, phytochemicals and mediterranean diet: a potential protective role against covid-19 through modulation of paf actions and metabolism. Nutrients. (2021) 13:1-25. doi: 10.3390/nu13020462

10. De Araújo Morais AH, Aquino JDS, Da Silva-Maia JK, Vale SHDL, MacIel BLL, Passos TS. Nutritional status, diet and viral respiratory infections: perspectives for severe acute respiratory syndrome coronavirus 2 . Br J Nutr. (2021) 125:851-62. doi: 10.1017/S0007114520003311

11. Jayawardena R, Misra A. Balanced diet is a major casualty in COVID-19. Diabetes Metab Syndr Clin Res Rev. (2020) 14:1085-6. doi: 10.1016/j.dsx.2020.07.001

12. Santos L. The impact of nutrition and lifestyle modification on health. Eur J Intern Med. (2021). doi: 10.1016/j.ejim.2021.09.020

13. Moludi J, Alizadeh M, Vayghan HJ, Naemi M, Rahimi A, Musavi R. The relationship between dietary inflammatory index (DII) and disease severity and inflammatory status: a case-control study of COVID-19 patients. $\mathrm{Br} \mathrm{J}$ Nutr. (2021). doi: 10.1017/S0007114521003214

14. Soy M, Keser G, Atagündüz P, Tabak F, Atagündüz I, Kayhan S. Cytokine storm in COVID-19: pathogenesis and overview of antiinflammatory agents used in treatment. Clin Rheumatol. (2020) 39:2085-94. doi: 10.1007/s10067-020-05190-5

15. Walton GE, Gibson GR, Hunter KA. Mechanisms linking the human gut microbiome to prophylactic and treatment strategies for COVID-19. $\mathrm{Br} \mathrm{J}$ Nutr. (2021) 126:219-27. doi: 10.1017/S0007114520003980

16. Merra G, Noce A, Marrone G, Cintoni M, Tarsitano MG, Capacci A, et al. Influence of mediterranean diet on human gut microbiota. Nutrients. (2021) 13:1-12. doi: 10.3390/nu13010007

17. Beck MA, Levandert OA, Handy J. Selenium deficiency and viral infection. J Nutr. (2003) 133:1463S-7S. doi: 10.1093/jn/133.5.1463S enthusiastic collaboration and our advisors from Harvard TH Chan School of Public Health Walter Willett, Alberto Ascherio, Frank B. Hu, and Meir J. Stampfer who helped us to design the SUN Project. Also, RP-A is grateful to have received a grant from Delegación del Gobierno para el Plan Nacional Sobre Drogas to conduct his Ph.D. studies.

18. Vaghari-Tabari M, Mohammadzadeh I, Qujeq D, Majidinia M, Alemi F, Younesi S, et al. Vitamin D in respiratory viral infections: a key immune modulator? Crit Rev Food Sci Nutr. (2021). doi: 10.1080/10408398.2021.1972407

19. World Health Organization. WHO EMRO Nutrition Advice for Adults During the COVID-19 Outbreak. (2021). Available online at: http://www.emro. who.int/nutrition/news/nutrition-advice-for-adults-during-the-covid-19outbreak.html (accessed October 28, 2021).

20. Peng. Vitamin C Infusion for the Treatment of Severe 2019-nCoV Infected Pneumonia - Full Text View - ClinicalTrials.gov. (2020). Available online at: https://clinicaltrials.gov/ct2/show/NCT04264533 (accessed July 26, 2021).

21. Meltzer DO, Best TJ, Zhang H, Vokes T, Arora V, Solway J. Association of vitamin $\mathrm{D}$ status and other clinical characteristics with COVID-19 test results. JAMA Netw Open. (2020) 3:e2019722. doi: 10.1001/jamanetworkopen.2020.19722

22. Skrajnowska D, Brumer M, Kankowska S, Matysek M, Miazio N, BobrowskaKorczak B. Covid 19: diet composition and health. Nutrients. (2021) 13:2980. doi: 10.3390/nu13092980

23. Iddir M, Brito A, Dingeo G, Del Campo SSF, Samouda H, La Frano MR, et al. Strengthening the immune system and reducing inflammation and oxidative stress through diet and nutrition: considerations during the covid-19 crisis. Nutrients. (2020) 12:1562. doi: 10.3390/nu12061562

24. Rizzo A, Sciorsci RL, Magrone T, Jirillo E. Exploitation of some natural products for the prevention and/or nutritional treatment of SARS-CoV2 infection. Endocr Metab Immune Disord Drug Targets. (2020) 21:1171-82. doi: 10.2174/1871530320999200831231029

25. Tavakol Z, Ghannadi S, Tabesh MR, Halabchi F, Noormohammadpour P, Akbarpour S, et al. Relationship between physical activity, healthy lifestyle and COVID-19 disease severity; a cross-sectional study. J Public Heal. (2021). doi: 10.1007/s10389-020-01468-9

26. PS C, Kodgire S, Paul V, Desai D, Kushwaha S, Sanyal D, Dasgupta S. Therapeutic potential of olive's bioactive compounds in COVID19 disease management. Acta Sci Microbiol. (2021) 4:98-111. doi: 10.31080/ASMI.2021.04.0879

27. Vu THT, Rydland KJ, Achenbach CJ, Van Horn L, Cornelis MC. Dietary behaviors and incident COVID-19 in the uk biobank. Nutrients. (2021) 13:2114. doi: 10.3390/nu13062114

28. Haupt-Jorgensen M, Buschard K. Can a gluten-free diet be partly protective for COVID-19 infection? APMIS. (2020) 128:558-9. doi: 10.1111/apm.13075

29. Abdulah DM, Hassan AB. Relation of dietary factors with infection and mortality rates of COVID-19 across the world. J Nutr Heal Aging. (2020) 24:1011-8. doi: 10.1007/s12603-020-1512-3

30. Batiha GES, Alqarni M, Awad DAB, Algammal AM, Nyamota R, Wahed MII, et al. Dairy-derived and egg white proteins in enhancing immune system against COVID-19. Front Nutr. (2021) 8: doi: 10.3389/fnut.2021.629440

31. Louca P, Murray B, Klaser K, Graham MS, Mazidi M, Leeming ER, et al. Modest effects of dietary supplements during the COVID-19 pandemic: insights from 445850 users of the COVID-19 Symptom Study app. BMJ Nutr Prev Heal. (2021) 4:149-57. doi: 10.1136/bmjnph-2021-000250

32. Kim H, Rebholz CM, Hegde S, Lafiura C, Raghavan M, Lloyd JF, et al. Plantbased diets, pescatarian diets and COVID-19 severity: A population-based case-control study in six countries. BMJ Nutr Prev Heal. (2021) 4:257-66. doi: 10.1136/bmjnph-2021-000272

33. Majumder D, Debnath M, Sharma KN, Shekhawat SS, Prasad GBK, Maiti D, et al. Olive oil consumption can prevent non-communicable diseases and COVID-19 : Review. Curr Pharm Biotechnol. (2021) 22:261-75. doi: $10.2174 / 1389201022666210412143553$ 
34. Perez-Araluce R, Martinez-Gonzalez MA, Fernández-Lázaro CI, BesRastrollo M, Gea A, Carlos S. Mediterranean diet and the risk of COVID19 in the 'Seguimiento Universidad de Navarra' cohort. Clin Nutr. (2021). doi: 10.1016/j.clnu.2021.04.001

35. Mohseni H, Amini S, Abiri B, Kalantar M, Kaydani M, Barati B, et al. Are history of dietary intake and food habits of patients with clinical symptoms of COVID 19 different from healthy controls? A case-control study. Clin Nutr ESPEN. (2021) 42:280-5. doi: 10.1016/j.clnesp.2021.01.021

36. El Khoury CN, Julien SG. Inverse association between the mediterranean diet and COVID-19 risk in Lebanon: a case-control study. Front Nutr. (2021) 8:707359. doi: 10.3389/fnut.2021.707359

37. Ahmadi MN, Huang BH, Inan-Eroglu E, Hamer M, Stamatakis E. Lifestyle risk factors and infectious disease mortality, including COVID-19, among middle aged and older adults: evidence from a community-based cohort study in the United Kingdom. Brain Behav Immun. (2021) 96:18-27. doi: 10.1016/j.bbi.2021.04.022

38. Trujillo-Mayol I, Guerra-Valle M, Casas-Forero N, Sobral Mm, Viegas O, Alarcón-Enos J, et al. Western dietary pattern antioxidant intakes and oxidative stress: importance during the SARS-CoV-2/COVID-19 pandemic. Adv Nutr. (2021) 12:670-81. doi: 10.1093/advances/nmaa171

39. Ponzo V, Pellegrini M, D'eusebio C, Bioletto F, Goitre I, Buscemi S, et al. Mediterranean diet and sars-cov-2 infection: is there any association? A proof-of-concept study. Nutrients. (2021) 13:1721. doi: 10.3390/nu13051721

40. Martínez-González MÁ. The SUN cohort study (Seguimiento University of Navarra). Public Health Nutr. (2006) 9:127-31. doi: 10.1079/PHN2005935

41. Redondo-Bravo L, Moros MJS, Sanchez EVM, Lorusso N, Ubago AC, Garcia VG, et al. The first wave of the COVID-19 pandemic in Spain: characterisation of cases and risk factors for severe outcomes, as at 27 April 2020. Eurosurveillance. (2020) 25:2001431. doi: 10.2807/1560-7917.ES.2020.25.50.2001431

42. Menni C, Valdes AM, Freidin MB, Sudre CH, Nguyen LH, Drew $\mathrm{DA}$, et al. Real-time tracking of self-reported symptoms to predict potential COVID-19. Nat Med. (2020) 26:1037-40. doi: 10.1038/s41591-020-0 916-2

43. Fuente-Arrillaga C de la, Ruiz ZV, Bes-Rastrollo M, Sampson L, MartinezGonzález MA. Reproducibility of an FFQ validated in Spain. Public Health Nutr. (2010) 13:1364-72. doi: 10.1017/S1368980009993065

44. Moreiras O, Cabrera L, Carbajal Á, Cuadrado C. Tablas de Composición de Alimentos: Guía de Prácticas. $17^{\mathrm{a}}$ ed. Madrid: Pirámide (2015).

45. Trichopoulou A, Costacou T, Bamia C, Trichopoulos D. Adherence to a mediterranean diet and survival in a Greek population. N Engl J Med. (2003) 348:2599-608. doi: 10.1056/NEJMoa025039

46. Carlos S, De La Fuente-Arrillaga C, Bes-Rastrollo M, Razquin C, Rico-Campà A, Martínez-González MA, et al. Mediterranean diet and health outcomes in the SUN cohort. Nutrients. (2018) 10:439. doi: 10.3390/nu10040439

47. Gouda AS, Adbelruhman FG, Sabbah Alenezi H, Mégarbane B. Theoretical benefits of yogurt-derived bioactive peptides and probiotics in COVID-19 patients - A narrative review and hypotheses. Saudi J Biol Sci. (2021) 28:5897905. doi: 10.1016/j.sjbs.2021.06.046

48. Paparo L, Bruno C, Ferrucci V, Punto E, Viscardi M, Fusco G, et al. Protective effects elicited by cow milk fermented with L. paracasei CBAL74 against SARS-CoV-2 infection in human enterocytes. J Funct Foods. (2021) 87:104787. doi: 10.1016/j.jff.2021.104787

49. Perdijk O, van Splunter M, Savelkoul HFJ, Brugman S, van Neerven RJJ. Cow's milk and immune function in the respiratory tract: potential mechanisms. Front Immunol. (2018) 9:1. doi: 10.3389/fimmu.2018.00143

50. Behzadipour Y, Gholampour M, Pirhadi S, Seradj H, Khoshneviszadeh M, Hemmati S. Viral 3CLpro as a target for antiviral intervention using milk-derived bioactive peptides. Int J Pept Res Ther. (2021). doi: 10.1007/s10989-021-10284-y

51. Norouzbeigi S, Yekta R, Vahid-Dastjerdi L, Keyvani H, Ranjbar MM, Shadnoush M, et al. Stability of severe acute respiratory syndrome coronavirus 2 in dairy products. J Food Saf. (2021) 41:e12917. doi: 10.1111/jfs.12917

52. Yekta R, Vahid-Dastjerdi L, Norouzbeigi S, Mortazavian AM. Food products as potential carriers of SARS-CoV-2. Food Control. (2021) 123:107754. doi: $10.1016 /$ j.foodcont.2020.107754
53. FAO. Per Capita Milk Consumption. (2017). Available online at: https:// ourworldindata.org/grapher/per-capita-milk-consumption (accessed October 29, 2021).

54. Deschasaux-Tanguy M, Srour B, Bourhis L, Arnault N, Druesne-Pecollo $\mathrm{N}$, Esseddik Y, et al. Nutritional risk factors for SARS-CoV-2 infection: a prospective study within the NutriNet-Santé cohort. BMC Med. (2021) 19:290. doi: 10.1186/s12916-021-02168-1

55. Zhou X, Chen D, Wang L, Zhao Y, Wei L, Chen Z, et al. Low serum calcium: a new, important indicator of COVID-19 patients from mild/moderate to severe/critical. Biosci Rep. (2020) 40:BSR20202690. doi: 10.1042/BSR20202690

56. Villa-Etchegoyen C, Lombarte M, Matamoros N, Belizán JM, Cormick G. Mechanisms involved in the relationship between low calcium intake and high blood pressure. Nutrients. (2019) 11:1112. doi: 10.3390/nu11051112

57. Di Filippo L, Formenti AM, Rovere-Querini P, Carlucci M, Conte C, Ciceri F, et al. Hypocalcemia is highly prevalent and predicts hospitalization in patients with COVID-19. Endocrine. (2020) 68:475-8. doi: 10.1007/s12020-020-02383-5

58. Torres B, Alcubilla P, González-Cordón A, Inciarte A, Chumbita M, Cardozo C, et al. Impact of low serum calcium at hospital admission on SARS-CoV-2 infection outcome. Int J Infect Dis. (2021) 104:164-8. doi: 10.1016/j.ijid.2020.11.207

59. Marazuela M, Giustina A, Puig-Domingo M. Endocrine and metabolic aspects of the COVID-19 pandemic. Rev Endocr Metab Disord. (2020) 21:495-507. doi: 10.1007/s11154-020-09569-2

60. Polzonetti V, Pucciarelli S, Vincenzetti S, Polidori P. Dietary intake of vitamin d from dairy products reduces the risk of osteoporosis. Nutrients. (2020) 12:1-15. doi: 10.3390/nu12061743

61. Bennouar S, Cherif AB, Kessira A, Bennouar DE, Abdi S. Vitamin $\mathrm{D}$ deficiency and low serum calcium as predictors of poor prognosis in patients with severe COVID-19. J Am Coll Nutr. (2021) 40:104-10. doi: $10.1080 / 07315724.2020 .1856013$

62. Rubin R. Sorting out whether vitamin D deficiency raises COVID-19 risk. J Am Med Assoc. (2021) 325:329-30. doi: 10.1001/jama.2020.24127

63. Grant WB, Lahore H, McDonnell SL, Baggerly CA, French CB, Aliano $\mathrm{JL}$, et al. Evidence that vitamin d supplementation could reduce risk of influenza and covid-19 infections and deaths. Nutrients. (2020) 12:988. doi: 10.3390/nu12040988

64. Gorji A, Khaleghi Ghadiri M. Potential roles of micronutrient deficiency and immune system dysfunction in the coronavirus disease 2019 (COVID-19) pandemic. Nutrition. (2021) 82:111047. doi: 10.1016/j.nut.2020.111047

65. Pollán M, Pérez-Gómez B, Pastor-Barriuso R, Oteo J, Hernán MA, PérezOlmeda M, et al. Prevalence of SARS-CoV-2 in Spain (ENE-COVID): a nationwide, population-based seroepidemiological study. Lancet. (2020) 396:535-44. doi: 10.1016/S0140-6736(20)31483-5

66. Elfström KM, Blomqvist J, Nilsson P, Hober S, Pin E, Månberg A, et al. Differences in risk for SARS-CoV-2 infection among healthcare workers. Prev Med Reports. (2021) 24:101518. doi: 10.1016/j.pmedr.2021.101518

Conflict of Interest: The authors declare that the research was conducted in the absence of any commercial or financial relationships that could be construed as a potential conflict of interest.

Publisher's Note: All claims expressed in this article are solely those of the authors and do not necessarily represent those of their affiliated organizations, or those of the publisher, the editors and the reviewers. Any product that may be evaluated in this article, or claim that may be made by its manufacturer, is not guaranteed or endorsed by the publisher.

Copyright (c) 2022 Perez-Araluce, Martínez-González, Gea and Carlos. This is an open-access article distributed under the terms of the Creative Commons Attribution License (CC BY). The use, distribution or reproduction in other forums is permitted, provided the original author(s) and the copyright owner(s) are credited and that the original publication in this journal is cited, in accordance with accepted academic practice. No use, distribution or reproduction is permitted which does not comply with these terms. 